\title{
Extent of Implementing the Characteristics of Professional Learning Communities at the UAE Special Education Centers
}

\author{
Rami Abdallah \\ British University in Dubai, UAE \\ https:// orcid.org/0000-0002-1449-0173 \\ Rawhi Mraweh Abdat \\ Ministry of Community Development, Dubai, UAE \\ https://orcid.org/0000-0002-6917-555X \\ Christopher Hill \\ Faculty of Education, British University in Dubai, UAE \\ https:/ / orcid.org/0000-0003-2436-1006
}

\begin{abstract}
Professional learning communities (PLCs) are formed on the basis of the perception that collaboration among educators is an essential factor to improve and develop the learning environment and students' outcomes (Hord, 1997; DuFour, 2004). Accordingly, the purpose of this study is twofold: First, we investigated the extent of practicing the characteristics of PLCs at special education (SE) centers in the United Arab Emirates (UAE). Second, we determined whether the PLC skills among SE educators vary on the basis of the type of educator, educational level, years of experience, and students' disability. We collected our data using Google Forms and with a pre-existing and tested questionnaire (Abdallah, 2021). After collecting filled-out forms from (151) educators, we conducted descriptive analysis and inferential statistics, including Mann-Whitney U and Kruskal-Wallis tests. Our results revealed that educators working with students with disabilities in SE centers have a high level of PLC skills in all domains. Educators' educational level, years of experience, and students' disabilities create significant differences in the practice of the PLC characteristics in SE centers. However, the type of educator has no significant difference in implementing these characteristics. Overall, this study can serve as a basis for further research on PLCs within the SE field and addresses the lack of knowledge of this topic. We conclude the effectiveness and readiness of PLCs as a new approach to handling and teaching students with disabilities in the UAE context.
\end{abstract}

Keywords: Professional learning communities (PLCs); PLC characteristics; special education; disability; teachers; educators 


\section{Introduction}

Several schools of thought have emphasized the necessity of collaboration and collegiality among educators to enhance their students' learning environment (Haggquist, 2018; Lippy, 2013). By contrast, isolation is considered the enemy of education and the most serious barrier to school transformation (Abdallah \& Hussein, 2016). Therefore, the concept of professional learning communities (PLCs) has emerged as a new culture and practice that reinforces cooperation and significantly affects student outcomes (Brown, 2019). In recent years, considerable research has addressed PLCs within general education, but only a few have focused on their implementation in special education (SE; Abdallah, 2021). PLCs can significantly improve teaching practices in general education and SE classes (Blanton \& Perez, 2011). At the national level, the United Arab Emirates (UAE) aims to develop its SE provision and ensure equal learning opportunities for all citizens. Consequently, the UAE government launched the national policy to empower people of determination (persons with disabilities) in 2017, which guarantees equal education under one of its main pillars as clear evidence of the governmental interest in the rights of people with disabilities, including the right to education.

The Ministry of Community Development (MOCD) in the UAE focuses on delivering high-quality and relevant services for persons with special needs to empower and prepare them to tackle their current and future challenges. The national policy to empower people of determination aims to support people with disabilities in different aspects and allow them to acquire education within a comfortable atmosphere. The policy follows a rights-based approach to ensure the availability of all requirements, enabling the SE field to deliver the required standards of learning to students with special needs. For this reason, improving SE teaching practices is a dire necessity to achieve comprehensive reform in such a relevant field. Currently, six federal governmental centers cater to special needs in the UAE, serving 655 students with intellectual disabilities, autism spectrum disorder (ASD), and multiple disabilities (Ministry of Community Development, 2021). Given these facilities, the MOCD can implement PLCs as a new approach to enhance the SE environment and learning outcomes for students with special needs in the UAE. Jones et al. (2013) indicated that implementing the PLC components within general education or SE can positively affect teachers' classroom practices and increase their participation in school activities, which leads to improved students' learning.

Prior studies confirmed that PLCs increase the efficacy of teachers and school capacity (Larson, 2016). Koonce (2018) described how operating the school with PLCs played a significant role in student learning and achievements. Accordingly, scholars attempted to present a comprehensive definition of PLCs, which mostly agreed on the idea of collaboration among educators as an essential factor to improve and develop the learning environment and students' outcomes (Hord, 1997; DuFour, 2004).

As the concept of PLCs can bring a new collective culture to schools, educators should grasp the characteristics of operating their schools as PLCs. Hord (1997) identified six dimensions that can assist teachers in implementing PLCs at their 
schools. These dimensions include shared and supportive leadership, shared values and vision, collective learning and application, shared personal practice, supportive conditions and relationships, and supportive conditions and structures. DuFour and Eaker (1998) also outlined six essential characteristics for operating schools as PLCs. These characteristics can be achieved through the presence of common goals and vision for all educators, a collaboration among educators regarding their self-improvement and students' learning, gathering information about the current practice and methods of improvement at the school level, the tendency to take actions for improvement among learning institutions, and working in accordance with the available results.

Vescio et al. (2008) reviewed ten studies about collaboration within PLCs. They described how all effective PLCs shared the following characteristics: participation in open collaboration, focus on students' learning among the groups, the empowerment of participants to exercise some authority in their learning and school leadership, and the continuous learning of participants to achieve their common goals.

PLCs focus on students' achievement as the essential goal of education (Manning, 2018). They can foster equity in learning, decrease absenteeism and the dropout rate, and improve student results in various subjects, including history, math, reading and language, and science (Cox, 2011).

SE can benefit from implementing the PLC components to work efficiently and effectively. For instance, Blanton and Perez (2011) explained how PLCs affect the integration of the efforts of SE teachers with other teachers at school by declining the isolation. Abdallah (2021) referred to the possibility of assigning SE teachers as the center of the PLC activities as they have considerable experience in handling students' learning problems.

Shipley (2006) confirmed the importance of collaboration between SE and general education members and how special educators should shift from isolation into teamwork to improve outcomes. The benefits of this collaboration are threefold: First, special educators possess several strategies that can support classroom management and solve students' behavioral problems. Second, they can help the general learning students who are at risk. Third, they can present new instructional methods for general educators. Another vital element in implementing PLCs is the role of SE administrators. After reviewing a group of studies on PLCs, Blanton and Perez (2011) provided the following five recommendations for administrators to benefit from implementing PLCs in SE:

- Support and facilitate collaboration among their teachers.

- Direct the efforts toward improving student learning for students with disabilities.

- Ensure a safe environment for teachers to discuss issues concerning students' learning and classroom.

- Use different motivational strategies to support their teachers' involvement in PLCs to improve their classroom practices.

- Understand that the occurrence of conflict is inevitable during collaboration. 
Day (2016) tried to identify the understanding of general education and SE teachers for PLC dimensions at two public elementary schools implementing PLCs. The above study used a quantitative descriptive design to investigate the existence of any differences between the perspectives of SE and general education teachers about PLCs. The sample consisted of ten SE teachers and 23 general education teachers. The results revealed that both teacher groups comprehend the process of PLCs and had positive perceptions toward PLCs with no significant differences.

Thacker (2013) analyzed the achievements of the fifth-grade SE students and teacher longevity in two Texas school districts. The findings revealed that the achievements of SE students increased at schools implementing PLCs because of the collaboration between general and special educators. Moreover, the results confirmed a relationship between the personal focus of teachers on their learning and the improvement of academic outcomes for students with special needs. However, the above study did not indicate any correlation between the implementation of PLCs and teachers' longevity.

East (2015) conducted a mixed-methods study to identify teachers' perceptions regarding the implementation of PLCs and their subsequent effects on improving students' learning. The site of this study was West Virginia, and the population was 211 educators from one K-8 school and three primary schools. The findings showed a strong and significant relationship between the level of implementation of PLCs and their level of effectiveness. The above study also suggested a group of procedures, which can enhance the influence of PLCs, such as scheduling and training among educators.

A further quantitative study (Topper, 2016) investigated the relationship between implementing the PLC components and students' literacy achievements. The above study was conducted in the urban school district in the south-central region of the US. The research participants were from middle and high schools. The results indicated a strong relationship between operating the schools as PLCs and enhancing adolescents' literacy.

Another mixed-methods study by Bitterman (2010) identified teachers' perceptions about the effect of PLCs on improving their teaching and learning skills. The above study included three middle science schools. The survey questionnaire was distributed to the selected participants composed of teachers in seventh grade. Then, the interviews were utilized to collect qualitative data from the participants. The results proved the possibility of enhancing teachers' skills and learning by involving them in PLCs. Accordingly, a group of requirements was determined for the effective implementation of PLCs. These requirements were motivation and interest in learning, appropriate organizational support, practicing inquiries, and work in accordance with a wellorganized development plan.

Al-Dhaheri and Mohammed (2013) examined the practice of different characteristics of PLCs at primary schools in Al Ain City in the UAE from the teachers' perspective. They determined whether responses related to the demographic variables vary using the professional learning assessment 
developed by Hipp and Huffman (2010) as a quantitative instrument. The survey involved 229 teachers. The results revealed a great extent of the PLC characteristics at Al Ain City primary schools.

Similarly, a mixed-methods study of Al-Taneji (2009) examined the realities and obstacles of the PLC characteristics at a group of elementary and secondary schools. Fifteen elementary and secondary schools were selected for the quantitative study, and semi-structured interviews for three teachers from six schools formed the qualitative element. The results of the quantitative data indicated that supportive and shared leadership and a supportive structure were the only PLC characteristics implemented among the surveyed schools. Accordingly, the above study shed light on the necessity of increasing the level of practicing PLC characteristics in schools.

Another qualitative study conducted by Jones et al. (2013) identified how implementing PLCs can contribute to building the cultural proficiency of educators and enhance their ability to respond to the needs of students within diverse and impoverished communities. The findings revealed that implementing PLCs could decrease the bias and cover the learning needs of students with general and special needs. Jenkins (2016) confirmed that the productive environment of learning and collaboration, an effective school leadership practice, the best use of teachers' capabilities, the reinforcement of teachers' efficacy, and the identification of school goals could support creating and sustaining PLCs. Spencer-Johnson (2018) identified the effect of practicing collaboration among educators who adopted PLCs on their skills of instruction, level of knowledge, and pedagogy. The finding of the above study revealed that training increases the performance of educators. Moreover, shared vision and effective school leadership were essential factors in creating effective PLCs.

Previous studies confirmed that PLCs could improve the learning environment for students at general education and SE and expand the reach of classroom practices. However, only a few investigated PLCs at SE centers in the UAE or other Arab countries (Day, 2016; Thacker, 2013; Topper, 2016). The present study uses the results and models of previous studies to investigate the extent of practicing the PLC characteristics at SE centers within the UAE context and present crucial recommendations and implications for practice. Our results contribute to the literature on the implementation of PLCs in the SE field in the $\mathrm{UAE}$, as this research topic is still new in Arab countries.

With the above literature review, this study investigates the PLC characteristics at SE centers in the UAE and highlights the differences among SE educator practices in teaching students with disabilities. We aim to identify the perceptions of SE teachers in the UAE about the extent of practicing the PLC components at their centers. We also determine whether teachers' perceptions on the type of educator, educational level, years of experience, and students' disability vary regarding the practice of the PLC characteristics in the SE field. 


\section{Methodology}

This study utilized a quantitative research methodology, specifically, a crosssectional survey.

\subsection{Sampling}

The total population of this study included 191 educators working in SE centers under the UAE government during the academic year 2020/2021. Among them, (154) were females, and (37) were males, with ages ranging from $26-50$ years. All educators were surveyed to ensure the collection of sufficient data related to the study purpose. After reviewing the filled-out questionnaires received from the educators, we considered (151) responses valid for statistical analysis. This study sample represented $(79 \%)$ of the total population. The participants included 151 educators ([84\%] SE teachers and [16\%] rehabilitation therapists). They were from six SE centers from different emirates. The majority had a bachelor's degree, and $52(34 \%)$ reported more than 15 years of experience. Finally, most participants indicated that they had been teaching students with intellectual disabilities (46\%). Table 1 presents the above participants' demographic information.

Table 1. Educators' demographic profile

\begin{tabular}{llc}
\hline Variable & Category & $N$ \\
\hline Type of educator & SE teacher & 127 \\
& Rehabilitation therapist & 24 \\
\hline Educational level & Diploma & 17 \\
& Bachelor's degree & 122 \\
& Graduate degree & 12 \\
\hline Years of experience & 1-5 years & 35 \\
& 6-10 years & 27 \\
& 11-15 years & 37 \\
& 16 years and above & 52 \\
\hline Students' disability & Intellectual disability & 70 \\
& ASD & 53 \\
\hline Total & Multiple disabilities & 28 \\
\hline
\end{tabular}

\subsection{Instrumentation}

We used the PLC questionnaire of Abdallah (2021), which combined the PLC dimensions mentioned by Hord (1997) and Dufour, Dufour, and Eaker (1998), to collect our data. This questionnaire included 36 close-ended questions that follow a five-point Likert scale: strongly disagree (1), disagree (2), neither agree nor disagree (3), agree (4), and strongly agree (5). We employed this survey questionnaire to examine the extent of practicing PLCs at SE centers in the UAE as perceived by educators. We also investigated the existence of any significant differences between educators' perceptions related to the category of educator, educational level, years of experience, and students' disability.

Validity refers to the extent to which any test accurately fulfills its objectives (Tatcher, 2010), and reliability is the degree of test consistency in measuring whatever it measures (Creswell, 2012). To achieve the validity of the research instruments, Abdallah (2021) consulted a panel of experts of educational 
management, leadership, and SE. The experts provided feedback regarding the questionnaire validity and its relevance to the research questions.

To achieve reliability, the author of the PLC questionnaire confirmed the internal consistency by calculating the Cronbach's alpha coefficients for all subscales $(n=$ 510 ) and determined an overall reliability coefficient of 0.97 , indicating high reliability (Abdallah, 2021). The questionnaire also included many variables, such as the presence of common goals; the vision, values, and mission for all educators at the school related to students' learning; and collaborative culture among educators. It also measured the extent of implementing collective inquiry by all educators about the current reality of the school and the recommended best educational practices, the extent of action orientation where all educators learn by doing, a commitment to continuous improvement, results orientation, and school leadership. We utilized social constructionism theory because it matches well with the concept of PLCs. Galbin (2014) mentioned that the main objective of social constructionism theory is to comprehend the experiences of individuals that formed collectively to understand the real world. Vygotsky (1978) explained how social constructivism theory considers the social interaction occurring within a particular culture or context a source of deep learning. The core of social constructionism is "the rejection of assumptions about the nature of mind and theories of causality and emphasizing the complexity and interrelatedness of the many facets of individuals within their communities" (Galbin 2014, p. 83). Therefore, social constructionism theory informs and supports the development of indicators of the data collecting instrument of the current study. It is compatible with the concept of PLCs as it perceives the collaboration between educators as a vital factor of professional development (Topper, 2016).

To facilitate the data collection, we reviewed the required procedures for conducting survey research. Gay et al. (2009) suggested the following steps of conducting survey research: stating the problem, constructing the questionnaire, pilot testing the questionnaire, preparing a cover letter, selecting participants, distributing the questionnaire, conducting follow-up activities, dealing with nonresponse, and tabulating questionnaire responses.

In light of the above steps, we translated the questionnaire into Arabic under the supervision of three expert translators because all the participants were native speakers of Arabic. Five bilingual professors from the College of Education, University of UAE, reviewed the Arabic version to ensure that the content was suitable and clear for all the participants. We also requested an official letter from the MOCD to distribute the questionnaire to the teachers electronically. The online questionnaire fully outlined our research objectives and the time required for completing the questionnaire.

\subsection{Data analysis}

We collected our data from the questionnaire and analyzed them using SPSS version 23.0. The results were represented in the form of descriptive statistics, including percentages, means, and standard deviation. We conducted MannWhitney $\mathrm{U}$ test to determine differences between two independent variables and Kruskal-Wallis tests to check the differences in mean scores for three or more independent variables. Moreover, we employed the Kolmogorov-Smirnov test to 
verify whether our data have a normal distribution. For the score interpretations, we used an interpretative scale, as shown in Table 2.

Table 2. Interpretive scale for the scores' degree

\begin{tabular}{ll}
\hline Mean Score & Degree \\
\hline $1-1.79$ & Extremely low \\
$1.8-2.59$ & Low \\
$2.6-3.39$ & Moderate \\
$3.4-4.19$ & High \\
$4.2-5$ & Extremely High \\
\hline
\end{tabular}

\section{Results}

\subsection{Levels of PLC characteristics}

Table 3. Educators' level of the PLC characteristics

\begin{tabular}{lcccc}
\hline Domains of PLCs & Mean & Std. Deviation & Level & Rank \\
\hline $\begin{array}{l}\text { Common goals, vision, } \\
\text { values, and mission }\end{array}$ & 3.71 & 1.26 & High & 7 \\
$\begin{array}{l}\text { Collaborative culture } \\
\text { Collective inquiry }\end{array}$ & 4.09 & 1.20 & High & 1 \\
Learning by doing & 4.06 & 1.07 & High & 3 \\
$\begin{array}{l}\text { Continuous } \\
\text { improvement }\end{array}$ & 4.05 & 1.08 & High & 5 \\
Results orientation & 4.06 & 1.09 & High & 3 \\
Center leadership & 4.07 & 1.08 & High & 2 \\
\hline Overall PLCs & 3.79 & 1.28 & High & 6 \\
\hline
\end{tabular}

The analysis results (Table 3) showed that the means of educators' responses were almost within the high level in all domains and the overall average of the PLC characteristics. The collaborative culture among educators ranked the highest $(\mathrm{M}$ = 4.09), followed by results orientation $(\mathrm{M}=4.07)$. By contrast, the presence of common goals, vision, values, and mission $(\mathrm{M}=3.71)$ and center leadership $(\mathrm{M}=$ 3.79) were the lowest domains. From the findings, the overall mean of 3.97 indicated that the educators in SE centers who participated in this study have a high level of PLC skills. 


\subsection{Testing differences among educators in the PLC characteristics}

The normal distribution of the results was checked by the Kolmogorov-Smirnov test, which indicated that the data drawn from this study were not normally distributed but had unequal variances. Therefore, we used non-parametric inferential statistics in testing differences in PLCs among educators in SE centers. We implemented Mann-Whitney $U$ test to determine differences for two independent variables and Kruskal-Wallis tests for three or more independent variables.

Table 4. Mann-Whitney $U$ test between the type of educator and PLC characteristics

Category Educators' implementing PLCs

\begin{tabular}{lcc}
\hline Type of Educator & Mann-Whitney U test & 1241.500 \\
SE teacher, $\mathrm{M}=4.06$ & $\mathrm{Z}$ & -1.471 \\
$\begin{array}{l}\text { Rehabilitation therapist, } \mathrm{M} \\
=3.51\end{array}$ & Asymp. sig. (two-tailed) & 0.141 \\
\end{tabular}

Table 4 shows the differences between educators' demographic profile and their practice of the PLC characteristics. The type of educator $(U=1241.500 ; p=0.141)$ had no significant differences with their practice of PLC characteristics at SE centers.

Table 5. Kruskal-Wallis test between educators' demographic profiles and PLCs

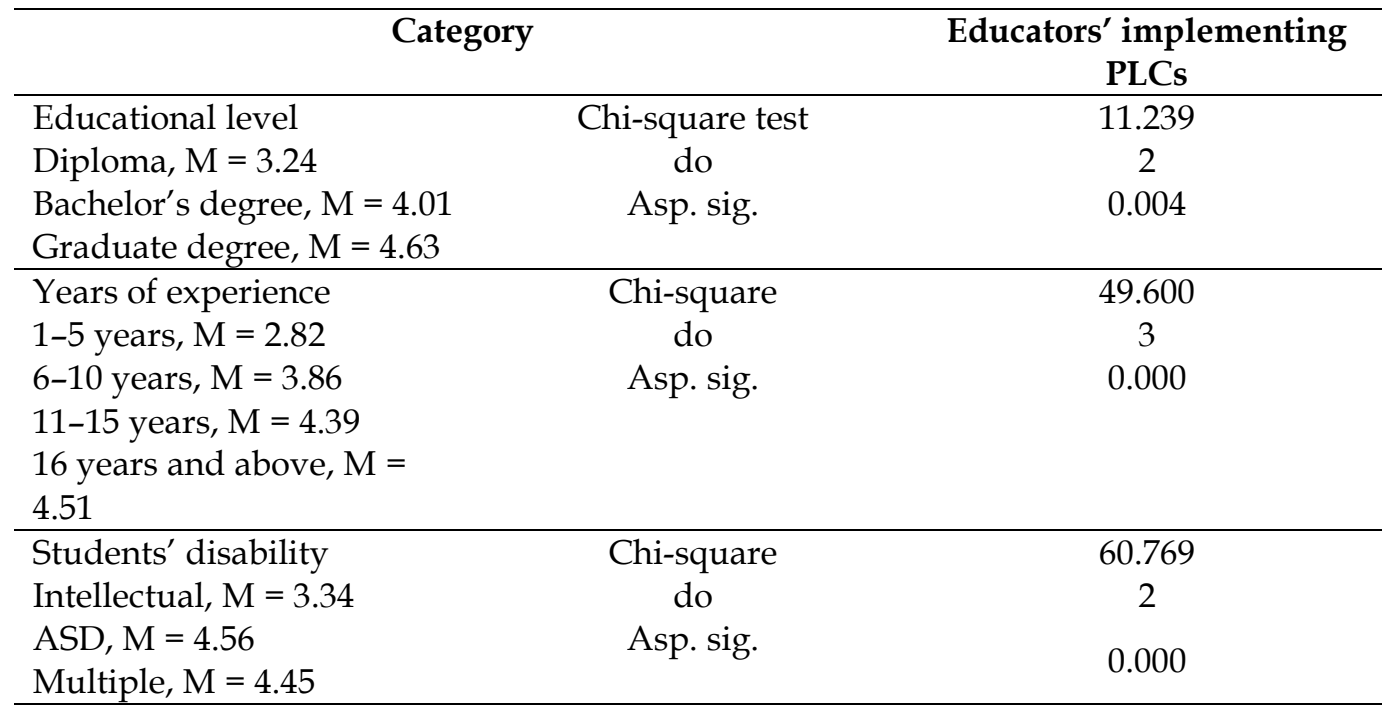

The Kruskal-Wallis test results (Table 5) revealed significant differences among educators in terms of the educational level $(\mathrm{X} 2(2)=11.239 ; p=0.004)$. The highest and least mean scores were by educators with graduate degrees $(M=4.63)$ and those holding diplomas $(\mathrm{M}=3.24)$, respectively.

Likewise, the results revealed significant differences among educators regarding years of experience $(X 2(3)=49.600 ; p=0.000)$. Generally, educators with long experience demonstrated more readiness to practice PLCs in their SE centers. 
Educators with 16 years of experience and above had the highest mean score (M $=4.51$ ), and those with less than five years of experience obtained the least mean score $(M=2.82)$. Finally, the educators who participated in the study exhibited significant differences concerning their students' type of disability $(X 2(2)=60.769$; $p=0.000)$. Educators of students with ASD reported the highest mean scores (M $=4.56)$, followed by educators of students with multiple disabilities $(\mathrm{M}=4.45)$. Educators of students with intellectual disabilities yielded the least mean scores $(\mathrm{M}=3.34)$.

\section{Discussion}

This study investigated the extent of practicing the characteristics of PLCs at SE centers and determined how significant the influence of educators' and students' characteristics on the implementation of PLCs. We determined that educators working in SE centers implement the basic principles of the PLC skills in their educational system. This finding reveals the existence of a fertile and encouraging educational environment in SE centers that paved the way to the PLC implementation as a new approach to enhancing the collaborative learning environment in the SE field.

Our results also showed that the domains related to common goals, vision, values, and mission, and center leadership were lower than the other domains. A possible reason is that SE centers follow the vision and mission of the MOCD and not their independent vision or mission. This reality highlights the need to train SE centers' principals on the basic principles of the PLC system and its implementation and follow-up mechanisms. The above findings on common goals and vision, values, and mission were similar to those of Spencer-Johnson (2018) and Jenkins (2016). Spencer-Johnson (2018) stated that having a shared vision and common goals and values is crucial in establishing PLCs among schools. Jenkins (2016) established a group of procedures for school leadership, which include the importance of having a shared vision and common goals and values to create and sustain successful PLCs.

However, we observed no significant differences among educators' perceptions of implementing PLC principles in terms of the type of educator. Thus, SE teachers and other therapeutic specialists follow a collaborative approach in the course of education and rehabilitation as their work requires them to be a team in establishing, implementing, and evaluating individualized educational plans for each student. This sequential process also requires every team member to know about the educational goals of all members outlined in the joint plan and work collaboratively to achieve them.

By contrast, we determined significant differences among educators regarding their educational level. A highly educated staff is more likely to implement PLC characteristics than those with low educational levels. Thus, educators with more years of experience are using the PLC techniques more than those with shorter years of experience. These results confirm the significance of having a commitment to continuous improvement by educators to enhance their level of pedagogy and achieve improved student outcomes (Abdallah, 2021; Abdallah \& Hussein, 2016). 
Finally, the type of students' disability significantly affects the implementation of the PLC characteristics by educators in SE centers. Educators of students with ASD and multiple disabilities are more likely to implement the PLC principles in their work than those of students with intellectual disabilities. This finding confirms the effectiveness of PLCs in facilitating the presence of shared personal practice, supportive conditions and relationships, and supportive conditions and structures among educators in SE centers and improving the level of collaboration as required (Haggquist, 2018; Lippy, 2013).

\section{Conclusion}

Almost all of the educators who participated in this study were highly aware of the PLC principles and ready to implement them in their respective SE centers. The overall PLC score $(M=3.97)$ and the seven subdomains $(M=3.71-4.09)$ indicated high levels of PLC characteristics among educators of students with disabilities. Thus, educators in SE centers in the UAE are ready to implement such a collaborative learning environment that can enhance their students' learning practices.

We determined statistically significant differences among educators' perception of the extent of the significance of the PLC characteristics found at SE centers pertinent to the educational level in favor of educators with graduate degrees and among educators regarding years of experience in favor of those with long years of experience. The study also found significant differences regarding students' type of disability in favor of educators of students with ASD and multiple disabilities. However, we observed no significant differences regarding the type of educator. These findings imply the existence of collaborative culture at SE centers and the possible shift from the traditional to the PLC model. Overall, the educational community is mentally prepared to adapt the PLC characteristics and new collaborative ways of imparting knowledge. Further training focusing on early career educators, diploma holders, and those who teach students with intellectual disabilities is required on the PLC skills to build upon this attitude. Additional training for principals regarding implementation, orientation, and follow-up is likewise recommended.

Overall, our findings provide valuable knowledge to decision-makers and stakeholders at the Supreme Committee for People of Determination Services in the UAE regarding the possibility of implementing the PLC principles in SE centers and the essential professional development requirements to ensure the best practice. However, this study is limited to educators of SE centers under the government. A replication of this study involving educators and principals from private centers in the UAE would provide further support for the generalizability of our findings.

\section{References}

Abdallah, M., \& Hussein, R. (2016). The Extent of Practicing Different Components of Professional Learning Communities at the Bani Kinanah Secondary Schools in Jordan [Doctoral dissertation, United Arab Emirates University]. UAEU scholarworks. https://scholarworks.uaeu.ac.ae/all_theses/468 
Abdallah, R. (2021). The Effectiveness of School Leaders' Professional Development Programs in Promoting the Components of Professional Learning Communities in Jordan Public Secondary Schools According to School Leaders' and Teachers' Perceptions and Practices [Doctoral dissertation, The British University in Dubai]. BUiD bspace. https://bspace.buid.ac.ae/handle/1234/1781

Al-Dhaheri, M. \& Mohammed, F. (2013). The Extent to which the Characteristics of Professional learning communities are found in cycle one Schools in Al - Ain from Teachers prospective [Doctoral dissertation, United Arab Emirates University]. UAEU scholarworks. https://scholarworks.uaeu.ac.ae/all_theses/80

Al-Taneiji, S. (2009). Professional learning communities in the United Arab Rmirates schools: Realities and obstacles. International Journal of Applied Educational Studies, 6(1), 16-29. https://search-proquest-com.uaeu.idm.oclc.org/scholarlyjournals/professional-learning-communities-unitedarab/docview $/ 203201635 /$ se-2 ?accountid $=62373$

Bitterman, T. (2010). Teacher perceptions of the impact of professional learning communities on teaching and learning in middle school science (Publication No. 758398458) [Doctoral dissertation, The University of Alabama]. PQDT Open. https:/ / search-proquestcom.uaeu.idm.oclc.org/dissertations-theses/teacher-perceptions-impactprofessional-learning/docview/758398458/se-2?accountid=62373

Blanton, L. P., \& Perez, Y. (2011). Exploring the Relationship between Special Education Teachers and Professional Learning Communities. Journal of Special Education Leadership, 24(1), 6-16. https://www.semanticscholar.org/paper/Exploring-theRelationship-between-Special-Teachers-BlantonPerez/358fe1995145b8fdca9c9e97a84228496dccf1cc

Brown, R. L. (2019). The Elementary Principal's Role in Professional Development and Learning Communities: How to Support Continual Professional Growth [Doctoral dissertation]. University of Wisconsin-Madison.

Cox, T. D. (2011). Teachers' Perspectives on Building a Professional Learning Community (Publication No. 857926432) [Doctoral dissertation, Walden University]. PQDT Open. https://search-proquestcom.uaeu.idm.oclc.org/dissertations-theses/teachers-perspectives-on-buildingprofessional/docview /857926432/se-2?accountid=62373

Creswell, J. W. (Ed.). (2012). Collecting qualitative data. Educational Research: Planning, Conducting, and Evaluating Quantitative and Qualitative Research. Pearson.

Day, K. M. (2016). General Education and Special Education Elementary School Teachers' Understanding of Professional Learning Communities (Publication No. 1761843945) [Doctoral dissertation, Walden University]. PQDT Open. https://searchproquest-com.uaeu.idm.oclc.org/dissertations-theses/general-educationspecial-elementary-school/docview /1761843945/se-2?accountid=62373

DuFour, R. (2004). "What is a professional learning community?". Educational Leadership, 61(8), 6-11.

DuFour, R., \& Eaker, R. (1998). Professional learning communities at work: Best practices for enhancing student achievement. National Education Service.

East, K. A. (2015). A study of professional learning communities: Characteristics of implementation and perceived effectiveness in improvement schools in West Virginia (Publication No. 1696782177) [Doctoral dissertation, Marshall University]. PQDT Open. https://search-proquestcom.uaeu.idm.oclc.org/dissertations-theses/study-professional-learningcommunities / docview/1696782177/ se-2?accountid=62373

Galbin, A. (2014). An introduction to social constructionism. Social Research Reports, 26, 82. 
Gay, L. R., Mills, G. E. \& Airasian, P. (2009). Educational research: Competencies for analysis and applications. Pearson.

Haggquist, L. L. (2018). An Exploration of the Perceptions of Teachers and Administrators on the Relationship between Professional Learning Community Practices and School Success. [Unpublished doctoral dissertation]. Brandman University.

Hord, S. M. (1997). Professional learning communities: Communities of continuous inquiry and improvement. Southwest Educational Development Laboratory. https://sedl.org/pubs/change34/plc-cha34.pdf

Hipp, K. K. \& Huffman, J. B. (2010). Demystifying professional learning communities: School leadership at its best. Rowman \& Littlefield Education.

Jenkins, C. (2016). Principals' processes of creating successful professional learning communities in high-performing elementary schools (Publication No. 1879697966) [Doctoral dissertation, Capella University]. PQDT Open. https://search-proquestcom.uaeu.idm.oclc.org/dissertations-theses/principals-processes-creatingsuccessful/docview $/ 1879697966 /$ se-2?accountid $=62373$

Jones, L., Stall, G., \& Yarbrough, D. (2013). The importance of professional learning communities for school improvement. Creative Education, 4(05), 357-361. https://doi.org/10.4236/ce.2013.45052

Larson, J. (2016). The relationship between South Dakota public school superintendents' perceptions of professional development principles and student achievement [Unpublished doctoral dissertation]. University of South Dakota.

Koonce, M. J. (2018). Principal engagement in the professional development process: The identification of barriers, resources, and supports. [Doctoral dissertation, University of Arkansas].

Lippy, D., \& Zamora, E. (2013). Implementing effective professional learning communities with consistency at the middle school level. National Forum of Educational Administration and Supervision Journal, 29(3), 51-72.

Manning, M. K. (2018). Improving Learning through Principal Professional Learning Communities [Unpublished doctoral dissertation]. East Carolina University.

Ministy of Community Development. (2021). Annual report for the department of rehabilitation and welfare for people of determination. Department of Rehabilitation and Welfare for People of Determination. https://www.mocd.gov.ae/en/opendata/statistics.aspx

Shipley, J. B. (2006). Professional Learning Communities: Where Does Special Education Fit in? [Doctoral dissertation, Eastern Michigan University]. EMU Senior Honors Theses \& Projects. https://commons.emich.edu/honors/31/

Spencer-Johnson, E. J. (2018). Professional Learning Communities: An Examination of Teachers' Perspectives on Professional Conversations and Student Learning (Publication No. 2055230592) [Doctoral dissertation, Western Connecticut State University]. PQDT Open. https://search-proquest-com.uaeu.idm.oclc.org/dissertationstheses/professional-learning-communitiesexamination/docview $/ 2055230592 /$ se-2 ?accountid $=62373$

Thacker, T. D. (2013). Professional learning communities: An analysis of fifth grade special education student achievement and teacher longevity in two Texas school districts (Publication No. 1443858060) [Doctoral dissertation, Texas A \& M University-Commerce]. PQDT Open. https://search-proquestcom.uaeu.idm.oclc.org/dissertations-theses/professional-learningcommunities-analysis-fifth/docview $/ 1443858060 /$ se-2?accountid $=62373$

Thatcher, R. W. (2010). Validity and reliability of quantitative electroencephalography. Journal of Neurotherapy, 14(2), 122-152. https://doi.org/10.1080/10874201003773500 
Three new solution tree books spotlight professional learning communities and their power to improve schools. (2008, Jun 03). Business Wire. https:/ / search-proquestcom.uaeu.idm.oclc.org/wire-feeds/three-new-solution-tree-booksspotlight $/$ docview $/ 444596784 /$ se-2?accountid $=62373$

Topper, J. C. (2016). The Relationship between Secondary Schools' PLC Characteristics and Literacy Achievement. Electronic Theses and Dissertations [Doctoral dissertation, Georgia Southern University]. GSU Campus Repository. https://digitalcommons.georgiasouthern.edu/etd/1498

Vescio, V., Ross, D., \& Adams, A. (2008). A review of research on the impact of professional learning communities on teaching practice and student learning. Teacher and Teaching Education: An International Journal of Research and Studies, 24(1), 80-91. https://doi.org/10.1016/j.tate.2007.01.004

Vygotsky, L. S. (1980). Mind in society: The development of higher psychological processes. Harvard university press. 


\section{Appendix \\ Questionnaire for Educators Working at Special Education (SE) Centers}

Dear educators,

This questionnaire is part of a study that aims to investigate the extent of practicing the characteristics of professional learning communities (PLCs) at SE centers in the UAE. PLCs are the fruit of collaborative commitment among educators (teachers and rehabilitation therapists) working as a team. They develop their capabilities to implement collective inquiry continuously and take appropriate measures to improve learning outcomes for their students. Your participation in filling out this questionnaire is highly appreciated, which will be of great significance in achieving our research objectives and improving professional practices in SE centers in the UAE.

We ensure that the provided data will be dealt with in complete confidentiality, and their use will be limited to carrying out statistical analysis for research purposes. If you have any inquiries related to the topic of the study or the items of the questionnaire, please contact the researchers via email at 20170028@student.buid.ac.ae or phone number_0558507631.

Your collaboration is highly appreciated.

A. Participant's demographic data: Kindly encircle the most appropriate answer.

\begin{tabular}{|c|c|}
\hline Type of educator & Educational level \\
\hline 1. SE teacher & 1. Diploma \\
\hline 2. Rehabilitation therapist & 2. Bachelor's degree \\
\hline & 3. Graduate degree \\
\hline Years of experience & Students' disabilities \\
\hline 1. 1-5 years & 1. Intellectual disability \\
\hline 2. $6-10$ years & 2. Autism spectrum disorder \\
\hline 3. $11-15$ years & (ASD) \\
\hline 4. 16 years and above & 3. Multiple disabilities \\
\hline
\end{tabular}

B. Presence of common goals and vision, values, and mission for all educators at their respective centers related to students' learning

\begin{tabular}{|r|l|l|l|l|l|l|}
\hline & \multicolumn{1}{|c|}{ Statement } & $\begin{array}{l}\text { Strongly } \\
\text { disagree }\end{array}$ & Disagree & $\begin{array}{l}\text { Neither } \\
\text { agree or } \\
\text { disagree }\end{array}$ & Agree & $\begin{array}{c}\text { Strongly } \\
\text { agree }\end{array}$ \\
\hline 1. & $\begin{array}{l}\text { We aim to accomplish } \\
\text { common goals at our center. }\end{array}$ & & & & & \\
\hline 2. & $\begin{array}{l}\text { We work in accordance } \\
\text { with a clear vision known } \\
\text { by all educators at our } \\
\text { center. }\end{array}$ & & & & & \\
\hline 3. & $\begin{array}{l}\text { All educators at our center } \\
\text { seek to achieve a group of } \\
\text { educational values. }\end{array}$ & & & & & \\
\hline
\end{tabular}




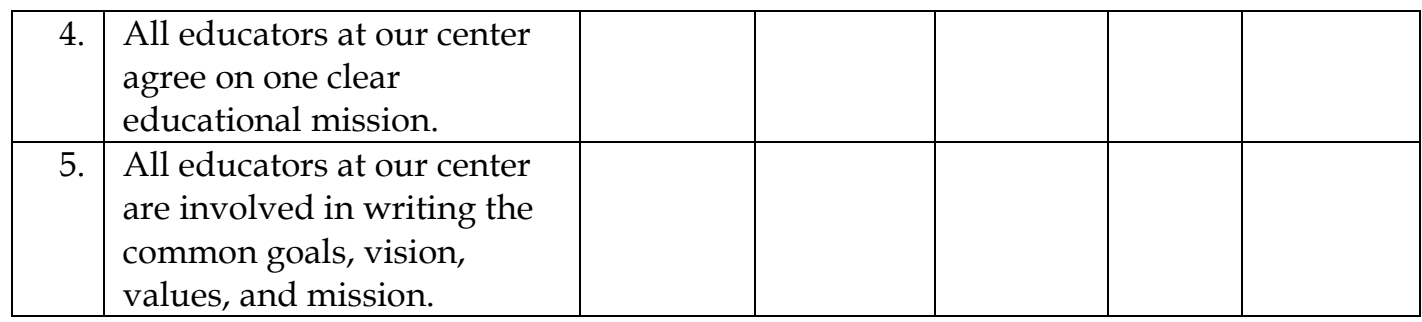

C. Presence of collaborative culture among educators

\begin{tabular}{|r|l|l|l|l|l|l|}
\hline & \multicolumn{1}{|c|}{ Statement } & $\begin{array}{l}\text { Strongly } \\
\text { disagree }\end{array}$ & Disagree & $\begin{array}{l}\text { Neither } \\
\text { agree or } \\
\text { disagree }\end{array}$ & Agree & $\begin{array}{c}\text { Strongly } \\
\text { agree }\end{array}$ \\
\hline 1. & $\begin{array}{l}\text { We work as a team with no } \\
\text { isolation from one another. }\end{array}$ & & & & & \\
\hline 2. & $\begin{array}{l}\text { Every educator at our } \\
\text { center is familiar with } \\
\text { teaching methods and } \\
\text { techniques utilized by other } \\
\text { educators from different } \\
\text { disciplines. }\end{array}$ & & & & & \\
\hline 3. & $\begin{array}{l}\text { We share experiences and } \\
\text { knowledge to enhance the } \\
\text { learning outcomes of our } \\
\text { students. }\end{array}$ & & & & & \\
\hline 4. & $\begin{array}{l}\text { The current concepts, } \\
\text { behavior, and habits of } \\
\text { educators foster teamwork. }\end{array}$ & & & & & \\
\hline 5. & $\begin{array}{l}\text { Every educator is aware of } \\
\text { his/her responsibilities } \\
\text { within the team. }\end{array}$ & & & & & \\
\hline
\end{tabular}

D. The extent of implementing collective inquiry by all educators about the current reality of their respective centers and the recommended best educational practices

\begin{tabular}{|r|l|l|l|l|l|l|}
\hline & \multicolumn{1}{|c|}{ Statement } & $\begin{array}{l}\text { Strongly } \\
\text { disagree }\end{array}$ & Disagree & $\begin{array}{l}\text { Neither } \\
\text { agree or } \\
\text { disagree }\end{array}$ & Agree & $\begin{array}{c}\text { Strongly } \\
\text { agree }\end{array}$ \\
\hline 1. & $\begin{array}{l}\text { All educators conduct a } \\
\text { collective inquiry about the } \\
\text { current reality of our center. }\end{array}$ & & & & & \\
\hline 2. & $\begin{array}{l}\text { All educators conduct a } \\
\text { collective inquiry about the } \\
\text { recommended best } \\
\text { educational practices. }\end{array}$ & & & & & \\
\hline 3. & $\begin{array}{l}\text { All educators participate in } \\
\text { designing a collective plan } \\
\text { to cover the different needs } \\
\text { of students. }\end{array}$ & & & & & \\
\hline 4. & $\begin{array}{l}\text { All educators collect and } \\
\text { analyze the available data }\end{array}$ & & & & & \\
\hline
\end{tabular}




\begin{tabular}{|r|l|l|l|l|l|l|}
\hline & $\begin{array}{l}\text { to evaluate the effectiveness } \\
\text { of the implemented } \\
\text { strategies. }\end{array}$ & & & & \\
\hline 5. & $\begin{array}{l}\text { Our collective inquiry is } \\
\text { based on dialogue and } \\
\text { respect for diverse views. }\end{array}$ & & & & & \\
\hline
\end{tabular}

E. The extent of action orientation where all educators learn by doing

\begin{tabular}{|r|l|l|l|l|l|l|}
\hline & \multicolumn{1}{|c|}{ Statement } & $\begin{array}{l}\text { Strongly } \\
\text { disagree }\end{array}$ & Disagree & $\begin{array}{l}\text { Neither } \\
\text { agree or } \\
\text { disagree }\end{array}$ & Agree & $\begin{array}{c}\text { Strongly } \\
\text { agree }\end{array}$ \\
\hline 1. & $\begin{array}{l}\text { All educators tend to } \\
\text { transfer their aspirations } \\
\text { and thoughts into real } \\
\text { practices within our center. }\end{array}$ & & & & \\
\hline 2. & $\begin{array}{l}\text { All educators believe in } \\
\text { taking action and working } \\
\text { to increase their knowledge } \\
\text { and experiences. }\end{array}$ & & & & & \\
\hline 3. & $\begin{array}{l}\text { All educators at our center } \\
\text { consider themselves } \\
\text { learners. }\end{array}$ & & & & & \\
\hline 4. & $\begin{array}{l}\text { All educators utilize what } \\
\text { they learn by doing in } \\
\text { setting the improvement } \\
\text { plan for our center, which is } \\
\text { connected to students' } \\
\text { learning. }\end{array}$ & & & & & \\
\hline 5. & $\begin{array}{l}\text { All educators believe that } \\
\text { collaboration and collective } \\
\text { inquiry will not be } \\
\text { beneficial without working } \\
\text { and taking action. }\end{array}$ & & & & & \\
\hline
\end{tabular}

F. Commitment to continuous improvement

\begin{tabular}{|c|l|l|l|l|l|l|}
\hline & \multicolumn{1}{|c|}{ Statement } & $\begin{array}{l}\text { Strongly } \\
\text { disagree }\end{array}$ & Disagree & $\begin{array}{l}\text { Neither } \\
\text { agree or } \\
\text { disagree }\end{array}$ & Agree & $\begin{array}{c}\text { Strongly } \\
\text { agree }\end{array}$ \\
\hline 1. & $\begin{array}{l}\text { All educators are } \\
\text { committed to the } \\
\text { continuous } \\
\text { improvement of their } \\
\text { students. }\end{array}$ & & & & & \\
\hline 2. & $\begin{array}{l}\text { All educators realize the } \\
\text { relationship between the } \\
\text { continuous professional } \\
\text { development that they } \\
\text { receive and their } \\
\text { students' learning } \\
\text { outcomes. }\end{array}$ & & & & & \\
\hline
\end{tabular}




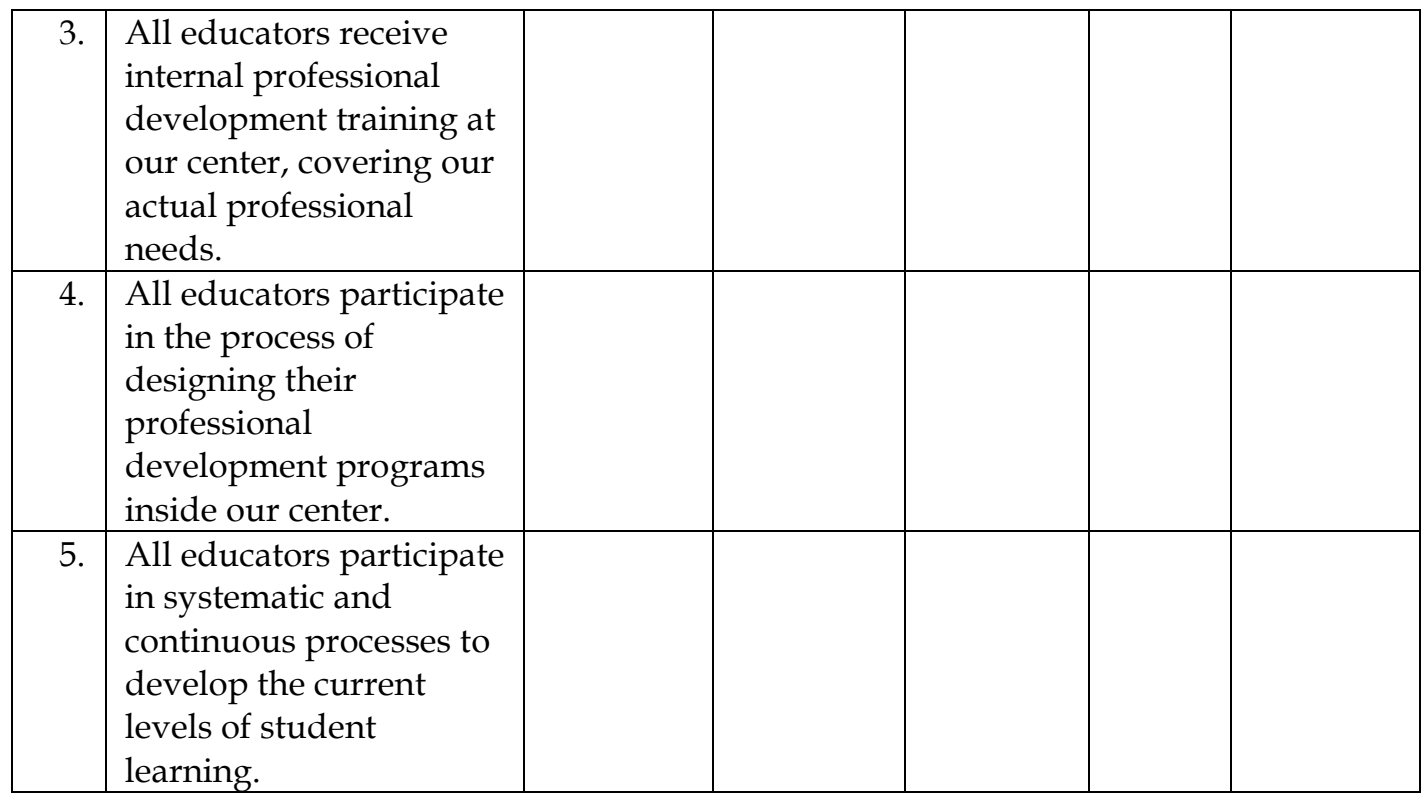

G. Results orientation

\begin{tabular}{|c|l|l|l|l|l|l|}
\hline & \multicolumn{1}{|c|}{ Statement } & $\begin{array}{l}\text { Strongly } \\
\text { disagree }\end{array}$ & Disagree & $\begin{array}{l}\text { Neither } \\
\text { agree or } \\
\text { disagree }\end{array}$ & Agree & $\begin{array}{c}\text { Strongly } \\
\text { agree }\end{array}$ \\
\hline 1. & $\begin{array}{l}\text { All educators } \\
\text { understand that results } \\
\text { are the most reliable } \\
\text { evidence of students' } \\
\text { improvement. }\end{array}$ & & & & & \\
\hline 2. & $\begin{array}{l}\text { All educators are } \\
\text { continuously involved } \\
\text { in the assessment } \\
\text { processes that include } \\
\text { all educational activities } \\
\text { at the center. }\end{array}$ & & & & & \\
\hline 3. & $\begin{array}{l}\text { We have an efficient } \\
\text { process to document } \\
\text { and save all results of } \\
\text { activities and initiatives } \\
\text { at the center. }\end{array}$ & & & & & \\
\hline 4. & $\begin{array}{l}\text { The decision-making } \\
\text { process at our center is } \\
\text { based on the available } \\
\text { results. }\end{array}$ & & & & & \\
\hline 5. & $\begin{array}{l}\text { All educators are } \\
\text { permitted to access the } \\
\text { results. }\end{array}$ & & & & & \\
\hline
\end{tabular}


H. Center Leadership

\begin{tabular}{|c|c|c|c|c|c|c|}
\hline & Statement & $\begin{array}{l}\text { Strongly } \\
\text { disagree }\end{array}$ & Disagree & $\begin{array}{l}\text { Neither } \\
\text { agree or } \\
\text { disagree }\end{array}$ & Agree & $\begin{array}{c}\text { Strongly } \\
\text { agree }\end{array}$ \\
\hline 1. & $\begin{array}{l}\text { The principal at our center } \\
\text { continuously ensures that } \\
\text { all educators understand } \\
\text { our center's common goals } \\
\text { and vision, values, and } \\
\text { mission related to students' } \\
\text { learning. }\end{array}$ & & & & & \\
\hline 2. & $\begin{array}{l}\text { The principal promotes } \\
\text { collaborative culture among } \\
\text { educators. }\end{array}$ & & & & & \\
\hline 3. & $\begin{array}{l}\text { The principal follows up } \\
\text { the implementation of } \\
\text { collective inquiry by all } \\
\text { educators about the current } \\
\text { reality of our center and the } \\
\text { recommended best practice. }\end{array}$ & & & & & \\
\hline 4. & $\begin{array}{l}\text { The principal fosters the } \\
\text { action orientation where all } \\
\text { educators learn by doing. }\end{array}$ & & & & & \\
\hline 5. & $\begin{array}{l}\text { The principal facilitates all } \\
\text { requirements that } \\
\text { encourage all educators to } \\
\text { be committed to continuous } \\
\text { improvement. }\end{array}$ & & & & & \\
\hline 6. & $\begin{array}{l}\text { The principal ensures that } \\
\text { all educators are working in } \\
\text { accordance with the } \\
\text { available results. }\end{array}$ & & & & & \\
\hline
\end{tabular}

